\title{
Percepciones de los católicos frente a las acusaciones de abuso sexual en la iglesia católica
}

\section{Perceptions of catholics in the face of accusations of sexual abuse in the catholic church}

\author{
Teresa Rivas-Fernández \\ Departamento de Antropología, Universidad de Chile \\ https://orcid.org/0000-0003-2441-0269 \\ teresa.rivas@ug.uchile.com
}

\begin{abstract}
Resumen
La religión Católica ha influido de una manera notable en la sociedad chilena desde tiempos remotos. Aunque últimamente su influencia no alcanzado tanta notoriedad, posiblemente por la exposición en los medios de comunicación de algunos casos de abusos sexuales apuntando como responsables a sacerdotes de la institución, causando así diversas reacciones en la población. Ante esta situación que experimenta la institución el presente artículo tiene como objetivo identificar el impacto que han producido en los creyentes católicos las polémicas para poder ver de que manera la iglesia puede actuar para evitar que en la organización se cometan actos indebidos relacionados a abusos y a encubrimiento dentro de la propia institución.
\end{abstract}

Palabras clave: iglesia católica, creyentes, abusos, polémicas, institución.

\begin{abstract}
The Catholic religion has had a remarkable influence on Chilean society since ancient times. Although lately his influence has not reached as much notoriety, possibly due to the exposure in the media of some cases of sexual abuse pointing as responsible to priests of the institution, thus causing various reactions in the population. Faced with this situation experienced by the institution, this article aims to identify the impact that the controversies have produced on Catholic believers in order to see how the church can act to prevent the organization from committing improper acts related to abuses and concealment within the institution itself.
\end{abstract}

Key words: catholic church, congregation, accusations, controversies, institution.

\section{Introducción}

El catolicismo ha sido parte de una de las religiones más importantes del mundo (Bargsted, 2003, Hungerman 2011 y La Parroquia Urbana, s/f), y este país tampoco ha estado ajeno a su gran importancia, especialmente palpable en la cantidad de adherentes, así como también en 
su gran influencia sobre algunas instituciones del país, aunque no en una forma tan fuerte como en los tiempos pasados, que podía influir sobre una mayor cantidad de aspectos y de otras instituciones principales. Participaba en decisiones más importantes relacionadas con asuntos culturales, sociales, políticos, y de la educación, etc. Las personas tenían una mayor compromiso con la institución respecto a la asistencia a las actividades, la celebración de fechas importantes relacionadas al catolicismo, al cumplimiento de los mandamientos que la religión establecía, y al seguimiento de los dogmas.

Hace algún tiempo atrás hemos visto como la presencia de la religión católica en el país se ha visto afectada, en especial por los últimas noticias que han involucrado a importantes figuras de la iglesia acusadas de actos indebidos de diversa gravedad en referencia a delitos sexuales. Los protagonistas envueltos en estos escándalos, en su gran mayoría incluye personas que han ejercido su trabajo en el sacerdocio, tanto en el pasado como en el presente, con algunos de ellos siendo muy reconocidos por la comunidad católica. Un caso notable fue el de Fernando Karadima, un párroco de la iglesia El Bosque, acusado de haber abusado sexualmente de jóvenes menores de edad (Pressly, 2018). Este fue el caso que comenzó impactando a la opinión pública y trayendo consigo otra serie de acusaciones de complicidad y encubrimiento en la estructura organizativa de la institución. Siendo una de las consecuencias más graves de las polémicas, la vulneración de la estima y el respeto que los adherentes le tenían a los sacerdotes, no solo afectando a los propios funcionarios, sino que además de que se han incrementado las críticas hacia la propia religión, ha desencadenado una mayor proliferación de insultos más fuertes por parte de personas no creyentes y se ha dañado la imagen de la iglesia católica para una gran parte de la nación, incluso hay quienes usan estas polémicas como material para ir más lejos y burlarse de la creencia en Jesúcristo y de otras figuras representativas de la religión católica que no tienen relación con las acusaciones de delito sexual.

En esta investigación se pretende tener más conocimiento con respecto al impacto que han generado los escándalos de la religión católica en lo referente a las acusaciones dirigidas a los altos cargos de la iglesia y como esta ha afectado a sus adherentes, en cuanto a su fe, a su compromiso con la religión y a su opinión con respecto a lo que está sucediendo. De este modo se podrá tener una comprensión más profunda sobre el estado actual de la religión católica en Santiago y ver si es que sus sostenedores tendrán que repensar algunos aspectos en torno a las reglas que existen para la asignación de los cargos más relevantes como el sacerdocio y el arzobispado o hacer modificaciones en sus lineamientos y fundamentos, todo esto con el propósito de evitar los abusos indebidos que pueden ejercer los funcionarios de la iglesia, de recuperar el compromiso de sus seguidores, de contribuir al proceso de reparación del dolor sufrido por las víctimas y de evitar el encubrimiento y la complicidad dentro de la institución, ya que se ha visto que una organización altamente jerarquizada como lo es la iglesia puede favorecer-además del abuso del poder- a la formación de alianzas, en las que se pueden ocultar y llevar a cabo cualquier tipo de fechoría sin que eso conlleve necesariamente una penalización justa para quien cometió el delito. 


\section{Metodología}

Para este estudio se realizó una encuesta anónima por Google forms dirigida a católicos de cualquier zona del país y se compartió por medio de distintas redes sociales, como Facebook, Gmail y Whatsapp. Con preguntas cuantitativas y cualitativas, las primeras fueron cuatro, en relación al género, la edad, la comuna donde reside la persona, nivel de estudios, si es que se estudió en una institución católica y la cantidad de veces a la semana de asistencia a la iglesia o a otro tipo de actividad relacionada al catolicismo. Las segundas preguntas cualitativas consisten en: la percepción de los escándalos en torno a la religión. Esa en cuanto a la primera pregunta cualitativa, mientras que la segunda con respecto a la disminución del compromiso, sobre como ha sucedido, y la última sobre los sentimientos que producen la críticas de quienes no son creyentes. Los datos se recopilaron durante abril y mayo de 2019 y después se analizaron con el software para análisis de datos cualitativos llamado Atlas.ti

Se recibieron 24 respuestas, de las cuales pudieron procesarse 21 en total. De acuerdo a los resúmenes de las respuestas, la mayoría de quienes respondieron son mujeres abarcando un $75 \%$, mientras que el porcentaje de respuestas de hombres fue de un $28,5 \%$, y un porcentaje de un $4,2 \%$ fue respondido por personas que se identificaron con otro tipo de género, la mitad de las personas tienen entre 18 a 25 años y la otra mitad entre 26 años o más. Pese a que se pretendía saber la percepción de gente desde distintas zonas del país, sólo hubo una persona que respondió desde la zona norte, en la comuna de Combarbalá, el resto provenía de Santiago, especialmente de la zona sur. En cuanto al nivel de estudio, la mayoría señaló tener una educación superior incompleta con 54,2\%, mientras que el 29,2 \% terminó los estudios medios, un 12,5 terminó la educación superior, sólo un 4,2\% no terminó la educación media. Para analizar la mayor influencia que pudo haber tenido la religión católica en los encuestados, se consultó sobre si había estudiado en una institución católica, pero la mayoría resultó estudiar en otro tipo de escuelas con un 65,2\%, mientras que solo el 37,5\% estudió en una escuela católica. En cuanto a la participación en actividades católicas, la mayoría solo participaba 2 veces a la semana con un $81,8 \%$, un porcentaje de $9,1 \%$ participaba entre 3 a 4 veces a la semana al igual que quienes participaban más de 4 veces que abarcaron el 9,1\% solamente.

Todas las respuestas procesadas fueron trasladadas y codificadas en el software para análisis de datos cualitativos Atlas.ti, para hacer el respectivo análisis, por medio de la asignación de los códigos que servían para ver cuáles respuestas estaban más relacionadas.

\section{Análisis}

De acuerdo a los análisis de las preguntas cualitativas, y ya con la base de las respuestas corregida previamente y para saber cómo los creyentes se han sentido con las noticias que involucran a los sacerdotes en acusaciones relacionadas con abusos sexuales, sobre como se 
ha visto comprometido su compromiso ante estas noticias y sobre las críticas de otras personas no creyentes.

En el caso de la primera pregunta: "Cuéntame sobre cómo has percibido los escándalos en los que se ha visto envuelta la religión Católica ¿Qué sentimientos te producen?”. Las mayores percepciones fueron de negatividad, desgano, indignación y pena, y en menor medida rabia y asco. De las diversas respuestas se puede extraer que las noticias no han dejado indiferente a nadie. Así, se puede ver que las percepciones de los creyentes en su gran mayoría pertenecen a sentimientos negativos ante las noticias, en especial hacia los propios acusados de abusos. En general la negatividad de los participantes, se asocia con lo inaceptable y repudiable que es "el uso de la confianza que han depositado los creyentes" y como los sacerdotes la han aprovechado junto con su posición como medio para ejercer este tipo de actos ilícitos desde hace mucho tiempo atrás.

La segunda pregunta: “¿Has visto disminuido tu compromiso en la institución ante las acusaciones que han salido a la luz sobre los altos cargos de la religión? Cuéntame cómo”. El compromiso si se ha visto afectado, lo que se ve reflejado especialmente en la poca asistencia en las actividades. Las respuestas mencionadas se relacionan con siguientes expresiones: desilusión, desconfianza, desgano, en segundo lugar hay algunos creyentes añaden "sentirse defraudados" y hay uno que mencionó tener "asco" hacia todos los curas. Aunque igual hay personas que demostraron ser más comprensivos con la institución o por lo menos más reflexivos, diciendo que: "son los humanos son los encargados de sus actos y no dudo que como líderes deberían dar el ejemplo pero son hombres y caen en fechorías pero no representan a la verdad que es Cristo y sus enseñanzas. Ya que en las escrituras jamás se justifican aquellas fechorías. Sin embargo, todo el mundo lo analiza como si fuera Dios quien permite estas atrocidades pero no es así es el hombre". También hay gente que sigue comprometida con las prácticas religiosas porque para ellos las iglesias a las que asisten siguen teniendo "vocación por los pobres y un actuar crítico ante estas polémicas." Lo cual se considera sensato tanto la respuesta de este participante, como el actuar que toman los sostenedores de la iglesia a la que asiste.

En la tercera pregunta: “¿Cómo te has sentido ante las críticas que realiza gente no creyente sobre las últimas polémicas en torno a la religión? ¿Qué sentimientos te producen?”. Con respecto a como se han sentido los creyentes con las distintas críticas por parte de gente no creyente, la mayoría expresó sentirse mal, pero que es entendible lo que otros opinen porque no todos tienen las mismas visiones pero que las críticas deben ser hechas con respeto para no herir la otros. Igualmente hay algunos que se muestran indiferentes antes las críticas, señalando que fe hacia Dios es más fuerte Hay otros pocos que consideran que los pronunciamientos de la gente no adherente corresponden y que es prudente que estos temas de abusos salgan a la luz pública, para que así se generen cambios verdaderos en la sociedad. 


\section{Conclusiones}

En base a los resultados de la metodología aplicada, se ha podido ver que las polémicas relacionadas con abusos sexuales ha sido mayoritariamente de rechazo hacia los propios sacerdotes, lo que no debe tomarse como un tema menor para la iglesia. Ya que sin duda estos funcionarios son parte fundamental de la estructura religiosa, funcionan como un guía espiritual para los creyentes, los ayudan a de algún modo a acercarse y a contactarse con Dios Parroquia Urbana (s/f) y el hecho que los adherentes ya no tengan deseos de relacionarse con los sacerdotes puede que contribuya a un declive del poder de la religión católica en el país, no tan solo por las acusaciones, sino que además por los encubrimientos y la complicidad dentro de la propia estructura organizativa .

Este rechazo hacia los sacerdotes se manifiesta con un decaimiento en el compromiso de los creyentes, como la inasistencia a las actividades relacionadas con la religión, al igual que con el desánimo de celebrar las festividades católicas, y a un decaimiento de la lealtad institucional hacia la iglesia. Aún así igual hay creyentes que siguen manteniendo su fe en Dios, argumentando que el motivo de la disminución en su compromiso, es que las prácticas indebidas son ejercidas por seres humanos. Lo que es así, porque según las escrituras, Dios dejó la posibilidad a los humanos de tener libre albedrío. Por ende los actos errados cometidos por humanos es responsabilidad de ellos mismos y se supone que este ser supremo no los justifica.

Respecto a este trabajo, no se pueden hacer conclusiones consistentes y sólidas sobre la postura de los creyentes dado el pequeño tamaño muestral y por algunas de las características de los encuestados ya que la mayoría es de Santiago. Pese a que se esperaba tener un mayor número de muestra, el estudio no logró tener un alcance óptimo y describe más las percepciones de ciertas zonas de la capital. No obstante, igualmente puede servir como una aproximación incipiente al impacto que han generado las polémicas en torno a la religión católica. Este tema merece mayor atención y estudio, porque es de contingencia, además de que nos afecta a todos en especial a los creyentes y porque tal como afirma Hungerman (2011) "La investigación sobre el impacto de la crisis de los abusos sexuales que atraviesa el catolicismo durante el último decenio está aún en su primera fase de desarrollo, con conclusiones todavía inciertas", y por lo tanto, es necesario dar cuenta de lo que sucede actualmente y proponer algo acerca de lo que sucederá probablemente en el futuro.

Por este motivo igual se valora el esfuerzo en exponer de manera respetuosa estos casos a la luz pública no para aumentar las burlas, ni las críticas sin argumentos sólidos en quienes no creen en la religión, sino para fomentar la reflexión, el pensamiento crítico. De este modo, se tomarán medidas más drásticas para expulsar de la institución a aquellos funcionarios que se han aprovechado de su posición en la estructura jerárquica, abusando de la confianza y la estima que les han tenido los creyentes y por otro lado para evitar el encubrimiento y la complicidad en la propia organización. 


\section{Nota}

Este trabajo de investigación se realizó dentro de la asignatura software para análisis de datos cualitativos en el primer semestre de 2019.

\section{Referencias}

Bargsted, M., Somma, N. \& Valenzuela, E. 2013. ¿En qué creen los chilenos? Naturaleza y alcance del cambio religioso en chile. Centro De Políticas Públicas UC. Nro 59: 1-20 pp. https://politicaspublicas.uc.cl/wp-content/uploads/2015/02/serie-n59-en-que-creen-los-chilen os-naturaleza-y-alcance-del-cambio-religioso-en-chile.pdf

Daniel Hungerman (2011). Substitution and stigma: evidence on religious competition from the catholic sex-abuse scandal. Nber working paper series 17589. National Bureau of Economic Research. https://www.nber.org/papers/w17589.pdf

Parroquia Urbana (s/f). Capítulo 1: El Catolicismo.

http://catarina.udlap.mx/u dl_a/tales/documentos/lar/vidal_r ha/capitulo1.pdf

Pressly, L (2018). Chile: "Cómo escapé de Fernando Karadima, el cura que abusó de mí durante décadas". Chile. Santiago: BBC Mundo.

https://www.bbc.com/mundo/noticias-america-latina-45508712 